\title{
Antonio Candido e a Academia Brasileira de Letras
}

\author{
ALBERTO VENANCIO FILHO ${ }^{I}$
}

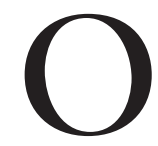

INGRESSO na Academia Brasileira de Letras se faz com uma carta que o candidato encaminha, acompanhada da relação das obras publicadas em livro. A exigência dessa iniciativa pessoal impede que muitos escritores se sintam constrangidos em apresentar a candidatura. Há a assinalar a situação frequente de que escritores que na mocidade se declararam críticos da Academia se candidatam na maturidade, renegando aquelas ideias. Incendiários na juventude e bombeiros na maturidade.

Há um episódio curioso em 1947, em reunião da diretoria da Associação Brasileira de Escritores. Surge um escritor com a revista da Academia e ocorre uma ideia: "Vamos redigir uma declaração afirmando o nosso propósito de não entrar jamais na Academia". Aurélio Buarque de Holanda, que achava legítimo aspirar à Academia, mesmo não sendo candidato, e seria eleito em 1961, preferiu abster-se de assinar. Todos os demais assinaram a declaração, com exceção de três signatários; os cinco outros acabaram sendo eleitos para a Academia.

Entretanto, em muitos casos ocorre um processo de cooptação, alguns acadêmicos sentindo que o candidato de grande prestígio certamente teria a unanimidade, senão a maioria dos votos, considero o candidato podendo assegurar um resultado favorável. Seria, certamente, a situação de Antonio Candido, se assim desejasse.

É praxe da Academia o presidente proferir no velório o "discurso de adeus". Com o sepultamento em São Paulo do acadêmico Fernando de Azevedo, coube ao acadêmico Francisco de Assis Barbosa proferir essa saudação e referiu-se ao acadêmico falecido: "como escritor, jornalista, ensaísta, crítico literário, sociólogo, mas sobretudo, professor, nos 30 volumes que deixastes ressaltada a figura excelsa do humanista".

Entre os presentes no velório se encontrava Antonio Candido, seu discípulo e grande amigo, visivelmente emocionado.

Após o discurso, num determinado momento Chico Barbosa, como carinhosamente era chamado, foi ao encontro de Antonio Candido e num canto passaram a conversar longamente. Depois informou que fizera um insistente convite para que Antonio Candido se candidatasse à vaga do mestre e grande amigo. Recusou delicadamente o convite, alegando que seria uma honra pertencer à Academia, ali tinha grandes amigos, e também uma honra suceder a Fernando de Azevedo, mas não tinha espírito associativo. Foi, talvez, a primeira de suas delicadas recusas. 
A Academia criou em 1943 o Prêmio Machado de Assis, destinado a premiar conjunto de obras de autor brasileiro vivo. Não há inscrições para o prêmio, decidindo o plenário livremente para a premiação. A Academia, ao conceder o Prêmio Machado de Assis, não revela nem consola escritores em início de carreira, mas ratifica o mérito de figuras ilustres da cultura brasileira. Até aquela data já tinham sido agraciados futuros acadêmicos como, entre outros, Fernando de Azevedo, Guimarães Rosa, Augusto Mayer, Silva Mello, Octávio Faria.

Em 1993 a Academia iria homenageá-lo com a outorga do Prêmio Machado de Assis.

O acadêmico que o saudou fez um resumo da sua vida e obra, destacando sua presença na revista Clima, a crítica literária na Folba da Manhã, no Diário de São Paulo e na Folha de S.Paulo, o concurso para a cátedra de literatura brasileiro, na Faculdade de Filosofia com tese sobre $O$ método crítico de Silvio Romero e a grande obra em dois volumes $A$ formação da literatura brasileira. Destacou a sua atuação como professor na Faculdade de Filosofia da USP, na Faculdade de Assis e no Instituto de Estudos da Linguagem da Faculdade de Campinas, e, ao concluir, lembrou que Fernando de Azevedo, seu mestre, amigo e admirador, recebera o Prêmio Machado de Assis em 1945 e só muito mais tarde ingressou na Academia.

Concluía a saudação: "Fernando de Azevedo, seu mestre, amigo e admirador, recebeu esta láurea em 1945 e só mais tarde aqui ingressou", como a sugerir o seu ingresso.

No discurso de resposta manifestava o seu "agradecimento pela atribuição de um prêmio tão importante quanto este, que traz o nome do nosso maior escritor e é concedido pela instituição que ele viveu e amou, com a capacidade de silencioso fervor que foi um dos traços de sua vida". E acrescentava que: "nesta Casa tenho bons amigos e eles sabem o quanto sou sensível a demonstrações como esta, que traduz uma avaliação honrosa do meu trabalho".

E prosseguia: "além disso, é agradável imaginar que o prêmio se situa de certo modo mais perto dos companheiros de atividade, isto é, os críticos literários, que sempre foram parte saliente desta Casa - desde Araripe Júnior, José Veríssimo e Silvio Romero até os de agora. Na Academia a crítica sempre encontrou terreno favorável". Analisou a crítica literária no século XIX e início do século XX e afirma: "esta tradição se reflete nas atividades da Academia, seja pela escolha dos patronos de suas cadeiras, seja pelos críticos que a ocuparam e ocupam".

Falando de Machado de Assis, afirma que:

[...] foi ele o teste de excelência de nossa literatura que sob este aspecto poderia ser dividida em duas partes, antes e depois dele. Por isso, ao estudar a Arcádia e o Romantismo como dois momentos decisivos na constituição da literatura brasileira, encerrei a investigação na altura de sua maturidade criadora. E até poderia dizer que um volume do meu livro Formação da Literatura Brasileira, são uma espécie de introdução a Machado de Assis, 
isto é, uma preparação para destacar o momento em que o Brasil pode apresentar ao mundo um escritor de estatura realmente universal em termos absolutos e conclui dizendo que é autor que "mais releio nesta altura da vida.

Em 2001 foi publicado um volume 3 Antonios e 1 Jobim, com o subtítulo de "História de uma geração", correspondendo ao encontro de Antônio Callado, Antonio Candido, Antônio Houaiss e Antônio Carlos Jobim. Os três primeiros eram da mesma idade, em torno dos setenta anos, Antônio Carlos Jobim sendo mais moço. $\mathrm{O}$ volume incluia a transcrição de uma reunião havida entre os quatros do Museu da Chácara do Céu, no bairro de Santa Teresa, no Rio de Janeiro, com uma conversa entre os quatro e também um depoimento individual de cada um. No caso de Antonio Candido, em sua residência em São Paulo, foi entrevistado por seu amigo Décio de Almeida Prado e sua esposa Gilda de Melo e Souza. A conversa era na extrema informalidade, tratando de vários assuntos - política, literatura, referências pessoas - mas não houve menção da Academia.

Naquela ocasião Antônio Houaiss já era acadêmico desde 1971 e Antônio Callado seria eleito no ano seguinte, havendo indicação de que Antônio Carlos Jobim teria desejado dela participar. Somente Antonio Candido não desejou pertencer a ela.

Indagado se não desejaria continuar a conversa com os dois Antônios no salão de chá do Petit Trianon, respondeu: "Essa lembrança muito me desvanece, mas como tenho a felicidade de encontrar vários em contexto não acadêmico, não chega a inverter minha vocação não associativa".

Antonio Candido acompanhava atentamente as atividades da Academia, aqui esteve ultimamente nas posses de seus amigos José Mindlin e Celso Lafer. Em 22 de março de 1993 ele felicitava a Academia "pela eleição praticamente total e unânime, do nosso querido Antônio Calado".

Em março de 1994, comentava com satisfação a eleição de Antônio Calado para a Academia. "Realmente foi uma aquisição de primeira ordem que prestigia a Academia. Depois de Sérgio Rouanet, Darcy Ribeiro, João Ubaldo Ribeiro e Antônio Calado, a Academia chama para o seu seio figura tão expressiva”.

E comentava as publicações da Casa. A Academia iniciou em 1923 um programa de publicações, a que deu o nome de Coleção Afrânio Peixoto, de obras eruditas, esgotadas, e muitas inéditas no campo da literatura e da história.

Foram editadas na ocasião no campo da literatura, entre outras, Prosopopeia, de Bento Teixeira; Música de Parnasso, de Manuel Botelho de Oliveira; obras de Gregório de Matos e Cartas jesuíticas. No setor de história, Viagem ao Brasil, de Hans Standen; Tratado da Terra do Brasil, de Pero de Magalhães Gandavo; Diálogo das Grandezas do Brasil.

A coleção sofreu certa descontinuidade, mas no ano de 2001 publicou várias obras esgotadas de acadêmicos falecidos que despertaram a atenção de Antonio Candido. 
A obra $A$ arte de furtar e o seu autor, de Afonso Pena Jr., uma das mais importantes contribuições da crítica de atribuição entre nós. Atribuída inicialmente a autoria ao Padre Antônio Vieira, várias outras autorias foram recordadas. Entre nós, João Ribeiro, no prefácio da Arte, atribuía a obra, sem maior convicção, a Tomé Pinheiro da Veiga, em confronto com o livro Fastigimia. Em 1917, Solidônio Leite examina as duas obras, mostrando a diferença fundamental entre ambas, e conclui pela autoria de Antônio de Souza Macedo.

Afonso Pena Jr., retomando os estudos de Solidônio Leite, desenvolve cerrados argumentos em dois volumes, o que pode ser considerado a mais importante obra de crítica de atribuição em nosso país.

O livro $A$ arte de furtar foi publicado em 1652, expondo os escândalos da administração pública na Restauração. Foi publicado como de autoria do Padre Antônio Vieira, embora o original mencionasse "um português anônimo zeloso da pátria”. Desde então a atribuição da autoria tem sido um enigma literário.

Recebendo $A$ arte de furtar e o seu autor, de Afonso Pena Jr., comenta a "nova edição do excelente livro de Afonso Pena Jr.", e rememorou que leu $A$ arte de furtar e o sen autor "quando saiu e sempre o considerei um dos momentos mais altos da crítica erudita brasileira, na esteira do opúsculo de Odorico Mendes, sobre o 'Palmeirim da Inglaterra'". E recordando a predileção de Afonso Pena Jr. por Montaigne, acrescentou que "uma pessoa, visitando o autor, viu vários cadernos cheios de anotações sobre Montaigne, autor que era de seu especial agrado". E indagava: "Será que os cadernos se perderam ou o autor os destruiu?". Os cadernos deveriam ser de grande interesse.

Intelectuais na encruzilhada corresponde à correspondência entre Alceu Amoroso Lima e Antônio Alcântara Machado entre 1927 e 1933. Trata-se de diálogo entre dois intelectuais de alto nível, o crítico literário recém-convertido ao catolicismo e que assumiria a liderança do laicato e o intelectual que já se projetara no romance e na crônica. Ambos revelando as inquietações no final da década de 1920 e as esperanças nos rumos do país, após a Revolução de 30. Das cartas de Antônio Alcântara Machado diria Augusto Frederico Schimidt que "revelaria a sua larga compreensão que assaltavam a esse angustioso e consciencioso crítico de literatura".

A introdução de Francisco de Assis Barbosa é uma análise desse momento político, com a particularidade de retratar a convivência que tivera com Antônio de Alcântara Machado no escritório no Rio de Janeiro, da Bancada Paulista por São Paulo Unido por ele dirigido. Completam o volume vários textos conexos de autoria de ambos e de Mário de Andrade, elucidativos do período e da correspondência.

Tomando conhecimento do livro de seu grande amigo Francisco de Assis Barbosa, Intelectuais na encruzilhada, comentava

[...] o belo livro de grande interesse, não apenas pela correspondência, mas apenas pelos materiais anexados. É uma publicação interessante, do nosso 
inesquecível Chico, intelectual da melhor categoria, cujos escritos são sempre bons e cuja Vida de Lima Barreto é um modelo de bibliografia literária.

E fazendo justiça: "Aliás a Academia Brasileira de Letras está de parabéns pela qualidade e beleza de suas publicações nesta fase".

Carlos de Laet (1847-1927), engenheiro de formação, foi professor do Colégio Pedro II e jornalista por várias décadas em diferentes jornais, mantendo uma coluna que ficou famosa: Microcosmo. Múcio Leão caracterizou bem a figura: "A do orador acadêmico, a do conferencista católico, a do jornalista puramente literário, a do jornalista de combate, usando as armas do humorismo e da sátira, a do polemista jamais excedido no Brasil, e em tudo, e sempre, a do estilista rútilo e perfeito". Com a sua atividade dispersa em jornais, sem reunião em livro, a sua figura foi se perdendo nos registros literários. Coube à Academia recuperar essa produção. Em 1953 a Academia editou o livro O frade estrangeiro e outros escritos, organizado e prefaciado por Múcio Leão. O volume de numerosas crônicas incluía duas conferências famosas, O frade estrangeiro, duas orações acadêmicas de saudação a Dantas Barreto e Dom Silvério Gomes Pimenta, e uma famosa polêmica com Camilo Castelo Branco.

Da extensa produção jornalística de Carlos de Laet, cerca de duas mil crônicas conhecidas, o volume contém cerca de 60 , divididos entre História, Política, Literatura e Vida Literária, Religião, Crítica Social, Sátira. Esses textos, nesse volume reunidos, permaneceram desconhecido nas novas gerações, como no caso de Antonio Candido. A sua importância, além de retratar episódios da nossa história a que assistiu, destaca-se também pela excelência do estudo.

Afinal, foi colaborador da Academia. Sim, colaborou com a Academia e teve publicada a monografia sobre Teófilo Dias, patrono da cadeira n.36, hoje ocupada pelo nosso confrade Fernando Henrique Cardoso. Essa monografia tinha sido editada em 1959, pelo Conselho Estadual da Cultura do Estado de São Paulo e estava inteiramente esgotada. Agora declara: "esta reedição veio de Celso Lafer, que ainda bem moço publicou numa daquelas coleções e seu primeiro trabalho, o Judeu em Gil Vicente. Tinha sido meu aluno e a partir de então fiz um amigo cuja solicitude não tem limite". E acrescentava Antonio Candido: "Aceitei o alvitre com prazer, inclusive devido a oportunidade de registrar a minha consideração pela Academia Brasileira de Letras, que acolheu este texto, acrescento mais uma às manifestações de apreço com que me tem honrado".

A Introdução de Antonio Candido é um estudo completo da vida e da obra do poeta, declarando que "ela visa, contudo, repor no curso de leituras uma obra historicamente até importante e esteticamente muito apreciável, contribuindo para que ele seja mais do que um nome".

A Academia continuou atenta às suas atividades. Por ocasião do centenário de nascimento em 1994 de Fernando de Azevedo, o presidente Josué Montello convidou-o para presidir uma mesa-redonda. Escusando-se por motivos de viagem, ele se congratulava com a Academia Brasileira "pela oportuna homenagem 
à memória de um dos intelectuais de mais alto porte que o Brasil teve neste século".

Quando em junho de 2007 recebeu a comunicação de que sua filha Laura de Melo e Souza ganhara um prêmio da Academia, escrevera: "Um galardão que será recebido por ela como um estímulo para continuar os seus trabalhos de historiadora. Para o pai é motivo de grande desvanecimento".

Ao receber em 2008 a ata da sessão em que foi votado um voto de congratulação pelo seu aniversário, agradecia “ser bem avaliado por uma coletividade intelectual de tão alto nível, eleva e conforta”. E referindo-se às palavras de um acadêmico, diz que: “estas palavras me desvaneceram pela generosidade e pela evocação do amigo já desaparecido, por meio de voz consagrado da Academia, continuam como saudade e inspiração, de maneira por assim atuante".

Nessa ocasião, o presidente Cícero Sandroni teve a feliz ideia de organizar uma caravana de acadêmicos para assistir em São Paulo à entrega do Prêmio Juca a Antonio Candido. Sensibilizado pela homenagem, escreveria ao presidente Cícero Sandroni:

Fiquei sensibilizado por sua presença e de seus confrades no ato da concessão do troféu Juca Pato. Ela foi para mim uma honra, um prazer e uma grata surpresa. Ver intelectuais de tal porte se deslocarem até São Paulo em atenção a mim com representantes da mais alta entidade cultural no domínio das letras, foi uma verdadeira consagração, a qual serei sempre agradecido, mesmo sabendo que non sum dignus.

Há uma praxe na Academia instituída a partir de 1910, por iniciativa de Mário de Alencar, da "sessão da saudade", por ocasião do falecimento de um colega. A morte de Antonio Candido promoveu manifestações que pareciam significar uma sessão da saudade. Falou em primeiro lugar o acadêmico Celso Lafer, seu ex-aluno e grande amigo que traçou um perfil completo da vida e da obra do homenageado, caracterizando-o "como uma das maiores referências intelectuais do Brasil. São de indiscutível envergadura suas contribuições para o entendimento do país, de sua literatura e do fenômeno literário".

Estuda algumas de suas obras e destaca o texto a análise “do papel da afirmação histórica dos direitos humanos, fundamento do direito, e função generalizada da criação ficcional e artístico, como um bem incompreensível, por ser uma necessidade básica”.

$\mathrm{O}$ acadêmico Alberto Venancio Filho estudou as relações de Antonio Candido desde o recebimento do Prêmio Machado de Assis em 1995, até a publicação em 2011 do volume de Poesias, de Teófilo Dias.

$\mathrm{O}$ acadêmico Cândido Mendes lamentava a perda de dois fundadores da crítica literária no Brasil, Eduardo Portella e Antonio Candido, para frisar que a obra de Antonio Candido é uma obra de maturidade "e que ele como crítico literário é também essencialmente um sociólogo". 
Chama a atenção para os 96 artigos que escreveu nos últimos anos na Folha de S.Paulo, fundamentais para quem pretende estudar o Antonio Candido jornalista. E conclui "que devemos a Antonio Candido a sua intuição verdadeira da dinâmica social do Brasil".

A acadêmica Ana Maria Machado, declarando só o ter conhecido em palestras e em livros, afirmava "sua admiração muito especial pela forma de escrever, pela clareza, pela limpidez". E acrescentava: "A clareza dessa limpidez foi muito importante, quando nos cursos de pós-graduação, quando se exigia um jargão literário cheio de preciosismo". E os escritos de Antonio Candido eram modelares, até como argumento para afirmar que se pode falar de tudo, procurando ser exato, límpido, ao alcance do estudante universitário, e concluía: “Antonio Candido desaparecendo fará cada vez mais falta ao país, com seu exemplo de dignidade pessoal, seu saber capaz de fina análise de livros e pessoas e sua preocupação com a cultura e sociedade brasileira".

Por ocasião do recebimento do Prêmio Machado de Assis, o orador que o saudou afirmou:

Permita-me, Sr. Presidente, falando em caráter estritamente pessoal, declarar que as portas desta Casa devem estar abertas para uma figura da estatura intelectual e da categoria moral de Antonio Candido.

Na sessão da saudade, o mesmo orador concluiu:

Permita-me, Sr. Presidente, novamente em caráter estritamente pessoal, parodiando aquela afirmação, imaginar que a Academia recebe hoje Antonio Candido postumamente, quase um membro honorário.

Alberto Venancio Filho é ensaísta, autor de vários livros, entre outros, Das arcadas ao bacharelismo e Notas republicanas. Membro da Academia Brasileira de Letras e do Instituto Histórico e Geográfico Brasileiro. @- avf@bpbc.com.br

Recebido em 7.6.2017 e aceito em 10.6.2017.

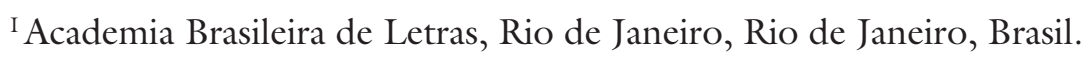

